\title{
Instruments and methods: a case study of ice core bubbles as strain indicators
}

\author{
John M. FEGYVERESI, ${ }^{1,2}$ Richard B. ALLEY, ${ }^{2}$ Donald E. VOIGT, ${ }^{2}$ Joan J. FITZPATRICK, ${ }^{3}$ \\ Lawrence A. WILEN ${ }^{4}$ \\ ${ }^{1}$ Terrestrial and Cryospheric Sciences Branch, U.S. Cold Regions Research and Engineering Laboratory, ERDC, Hanover, \\ NH 03755, USA. Email: fegy.john@gmail.com; john.m.fegyveresi@usace.army.mil \\ ${ }^{2}$ Department of Geosciences and Earth and Environmental Systems Institute, Pennsylvania State University, University Park, \\ PA 16802, USA \\ ${ }^{3}$ Ceosciences and Environmental Change Science Center, USGS, Denver, CO 80225, USA \\ ${ }^{4}$ Department of Mechanical Engineering and Materials Science, Yale University, New Haven, CT, USA
}

\begin{abstract}
Measurements of a sample from $\sim 580 \mathrm{~m}$ depth in the WAIS Divide (WDC06A) ice core reveal that bubbles are preferentially elongated in the basal plane of their parent grain, as expected if bubble shape preserves the record of dominant basal glide. This suggests that a method using bubbles as strain gauges could provide insights to grain-scale ice deformation. We introduce a technique using fabric and image analyses of paired thin and thick sections. Comparison of the crystallographic orientations of $\mathbf{1 4 8}$ grains and the shape orientations of 2377 intragrain bubbles reveals a strongly preferred elongation of bubbles in the grain basal planes $\left(R^{2}=0.96\right)$. Elongation magnitudes are consistent with a balance between ice flow deformation and diffusive restoration, with larger bubbles more elongated. Assuming bubbles record ice strain, grains with greater resolved stress on their basal planes from the far-field ice flow stresses show greater deformation, but with large variability suggesting that heterogeneity of the local stress field causes deformation even in unfavorably oriented grains. A correlation is also observed among bubble elongation, grain size, and bubble size, explaining a small but significant fraction of the variance $(P<0.05)$, with implications for controls on ice deformation, as discussed here.
\end{abstract}

KEYWORDS: glaciological instruments and methods, ice core, ice crystal studies, ice dynamics, ice physics

\section{INTRODUCTION}

Grain-scale processes are important in controlling the deformation of ice in glaciers and ice sheets, through effects on the flow law and formation of lattice-preferred orientations (e.g., Duval and others, 1983; Budd and Jacka, 1989; Van der Veen and Whillans, 1994, Goldsby and others, 2001). Accurately observing and characterizing the distribution of deformation at the grain scale remains challenging, however, especially at the low strain rates commonly observed in upper parts of ice sheets. Techniques applied to this challenge have included various in situ and experimental deformation studies of nearly 2-D samples (e.g. Azuma and Higashi, 1985; Wilson and others, 2014), modeling (e.g. Zhang and others, 1994a, 1994b; Montagnat and others, 2014; Llorens and others, 2016a, 2016b) and interpreting the observed characteristics of ice core samples (e.g., Alley, 1992, Kipfstuhl and others, 2006; 2009; Weikusat and others, 2009). Important questions remain, however, particularly about the flow law, and the distribution of stress on individual grains. Here, we develop a complementary technique to those already applied, assessing the suitability of measured bubble elongations in ice core samples as indicators of local strain.

Deformation of surrounding bulk ice deforms enclosed bubbles. The resulting bubble elongation is opposed by diffusive processes, which tend to restore bubbles toward spherical form (Alley and Fitzpatrick, 1999). The shape of a bubble in deforming ice thus integrates the recent history of the balance between deformation and diffusion. Magnitudes and directions of bubble elongation and differences between elongations of bubbles in adjacent grains, provide quantitative information on grain-scale processes.

We find variations in elongation of bubbles fully contained within individual grains suggesting that faster deformation occurs in larger grains and in grains with larger resolved shear stress on their basal planes, but with large grain-tograin variability. Notable uncertainties remain, as discussed below, but we conclude that this technique can provide useful information, motivating further research.

\section{BACKGROUND}

Elongated bubbles are observed in ice cores, especially those sampling rapidly deforming ice (e.g., Hudleston, 1977; Russell-Head and Budd, 1979; Alley and Bentley, 1988; Fitzpatrick, 1994; Alley and Fitzpatrick, 1999; Voigt and others, 2003), and this elongation rather clearly records the deformation of the surrounding ice (Gay, 1968; Nakawo and Wakahama, 1981; Alley and Fitzpatrick, 1999). As deviatoric stresses are not transmitted through bubbles and thus are enhanced around them, bubbles deform more rapidly than the bulk of the surrounding ice (Gay, 1968; Alley and Fitzpatrick, 1999). For uniaxial extension (and by analogy, any irrotational stress state), bubbles experience a strain rate of $\sim 5 / 3$ faster than ice but in the same direction 
(Alley and Fitzpatrick, 1999). For simple shear, bubbles first elongate at $45^{\circ}$ to the shear plane and then rotate toward the shear plane, again deforming $\sim 5 / 3$ faster than the surrounding ice.

Physical understanding and available data indicate that bubble shapes can be used to diagnose recent strain rates for ice even in the presence of diffusive processes. Mass transfer of molecules through lattice, surface and vapor diffusion driven by curvature and surface tension acts to restore elongated bubbles toward spherical, at a rate that increases monotonically with bubble elongation, but asymptotically approaches a maximum value (Alley and Fitzpatrick, 1999; Fegyveresi, 2015). Thus, under constant stress, a bubble either will evolve to a steady form in which deformation balances diffusion, or, if the deformational elongation rate exceeds the maximum diffusional restoration rate, continue to elongate without limit. (In practice, small inhomogeneities in deformation cause exceptionally elongated bubbles to 'pinch off' into multiple smaller bubbles). Larger initial bubble sizes, lower temperatures and more rapid ice deformation favor greater bubble elongation (Alley and Fitzpatrick, 1999; Gow, 1968a; 1968b).

We have observed very large bubble elongations (measured as aspect ratios $>2$ and in some cases approaching 10) (e.g., Alley and Fitzpatrick, 1999; their Fig. 1c), but bubbles in most ice core samples from typical deep-coring sites are only slightly nonspherical, consistent with a trend toward steady-state bubble shapes. In all such cases, if the cumulative diffusion and bubble deformation are sufficiently large to reset any bubble orientation inherited from firn processes or from complex histories (including bubbles switching between grains as grain boundaries migrate), the orientation of the bubble is expected to depend on the strain-rate field causing deformation (Gay, 1968; Alley and Fitzpatrick, 1999). Elongation of a bubble fully contained within a grain thus reveals the rate and direction of deformation of that grain. Differences in deformation rate between grains then can be used to test hypotheses for grain-scale interactions in ice deformation (e.g., Van der Veen and Whillans, 1994), as discussed below.

For ice deforming primarily by dislocation glide, strain rate under specified stress may be as much as two orders of magnitude or more faster on basal planes (perpendicular to the C-axis) than in other directions (Azuma and Higashi, 1985; Weertman, 1983; Duval and others, 1983). For a single crystal, this deformation rate depends on the resolved shear stress on the basal plane (Alley, 1988; Cuffey and Paterson, 2010). In uniaxial compression, the resolved shear stress is proportional to the Schmid factor, $S=\cos \phi \sin \phi$, with $\phi$ the angle between the $c$-axis and the vertical stress axis; $S$ has a maximum at $45^{\circ}$ and tends to zero for basal planes parallel to $\left(0^{\circ}\right)$ or perpendicular to $\left(90^{\circ}\right)$ the applied stress (Bouchez and Duval, 1982; Jacka and Maccagnan, 1984; Azuma and Higashi, 1985; Alley, 1988; Trickett and others, 2000).

In deforming polycrystals, differences in basal-plane orientations between adjacent grains or in localization of slip on active glide planes (e.g., Readings and Bartlett, 1971) lead to incompatibilities favoring formation of overlaps or gaps, which must be removed by diffusion, rotation, or other processes (e.g., Azuma and Higashi, 1985). Grain rotations are especially important in generating lattice preferred orientations (c-axis fabrics), with $c$-axes moving towards compressional and away from tensional axes, and with the rigid-body rotation of simple shear bringing $c$-axes toward the normal to the shear plane (e.g., Azuma and Higashi, 1985; Alley, 1988; 1992; Llorens and others, 2016a; 2016b; Qi and others, 2017). In turn, these grain-scale interactions cause the local stress state to differ from the mean for the entire sample, generating differences between far-field and local stress, with the corresponding variability in deformation rate that should be recorded in bubble elongation.

Various models have been proposed for approximating some aspects of this variability (e.g. Van der Veen and Whillans, 1994; Montagnat and others, 2014). These include the Taylor (or Voigt) model, in which each grain supports the same stress, yielding different deformation rates in adjacent grains with different orientations (Voigt, 1928) and the Reuss or static model, in which each grain experiences the same strain rate and thus supports different stress (Reuss, 1929). Actual behavior averaged across many grains is expected to fall between these in most cases (Montagnat and others, 2014), but with the exact behavior not known.

Grain size also may affect deformation within individual grains, and be recorded in bubble elongation. Cuffey and others (2000) provided strong evidence that ice with smaller grains deforms more rapidly, but this may result from processes linked to grain-boundary sliding (Goldsby and Kohlstedt, 2001). From dislocation mechanics and observations in ice and other materials (e.g., Baker and others, 1996), grain boundaries impede dislocation glide and thus deformation in most cases. Hirth (1972) summarized the general situation: 'The dislocation near an interface has a strain field extending into both media A and B. The strain energy in the harder medium is larger per unit displacement because the elastic constants are larger. Hence a dislocation in the softer medium is repelled from the interface to reduce the energy of the system, while a dislocation in the harder medium is attracted to the interface for the same reason.' In glaciers, both ' $\mathrm{A}$ ' and ' $\mathrm{B}$ ' are ice, and a gliding dislocation is generally moving on a favored plane for easy glide with high likelihood that the adjacent grain is not optimally oriented for that dislocation, so the adjacent grain is 'harder', causing dislocations to be repelled from the interface. Observations show dislocation pileups adjacent to grain boundaries arising from this repulsion (Baker and others, 1996; 2000). We note that Baker and others $(1996 ; 2000)$ are among those who have shown that grain boundaries also serve as sources of dislocations at sufficiently high stresses, but that the clear evidence of pileups near grain boundaries suggests a grain-size dependence of deformation.

Here, using a newly developed technique to analyze a 'hybrid' thick-/thin-section, we present the results of a detailed study of bubbles and grains in a sample prepared from a depth of $\sim 580 \mathrm{~m}$ in the West Antarctic Ice Sheet (WAIS) Divide deep core: WDC06A. The WDC06A coring site is located at $79^{\circ} 28.058^{\prime} \mathrm{S}, 112^{\circ} 05.189^{\prime} \mathrm{W}, \sim 24 \mathrm{~km}$ on the Ross Sea side of the ice flow divide with the Amundsen Sea drainage (Conway and Rasmussen, 2009; Fitzpatrick and others, 2014). Mean annual surface temperature is $\sim-30{ }^{\circ} \mathrm{C}$, and annual accumulation is $\sim 22 \mathrm{~cm}$ ice $\mathrm{a}^{-1}$. The ice thickness is $\sim 3455 \mathrm{~m}$, but coring was stopped at 3405 $\mathrm{m}$ to avoid the release of borehole fluid to the thawed bed (Fitzpatrick and others, 2014; Cuffey and others, 2016). Deformation includes vertical compression and along-flow extension with slight lateral convergence over the flowline leading to the site. 
We find that the bubbles display an elongation, preferentially oriented in the basal plane of the enclosing grain, with slightly greater elongation observed in larger bubbles, and for bubbles within larger grains and those with a larger Schmid factor.

\section{METHODS AND PREPARATION}

\section{Thick-section preparation for bubble analysis}

We modified our techniques (Fegyveresi and others, 2011; 2016) for preparing bubble 'thick sections' and grain 'thin sections' to allow coordinated interpretation of both. Here, we applied this technique to a single sample of ice from the WDC06A core. Typical ice thick-sections prepared for bubble analyses are $\sim 1.5 \mathrm{~mm}$ in thickness and are digitally photographed while illuminated on a side-lit, mounted stage. Typical ice thin-sections prepared for grain analyses are $\sim 0.3-0.5 \mathrm{~mm}$ in thickness (see also Fitzpatrick and others, 2014), and are observed in transmitted plane-polarized and cross-polarized light.

At the National Science Foundation Ice Core Facility (NSF-ICF; formerly the National Ice Core Laboratory), we used a band saw to cut a vertically-oriented bubble thicksection $\sim 10 \mathrm{~cm}$ long $\times \sim 6 \mathrm{~cm}$ wide $\times \sim 5 \mathrm{~mm}$ thick, from a depth of $\sim 580 \mathrm{~m}$ in the WDC06A core (measured depth range $579.02-579.12 \mathrm{~m})$. We label this section here as 'Vertical Hybrid Section 580', or simply VHS-580). One face of this sample was smoothed with a sledge-type microtome and then affixed to a glass slide using a rapid-curing cyanoacrylate adhesive. Following the procedures described by Fegyveresi and others $(2011 ; 2016)$, the sample was first microtomed to $\sim 1.5 \mathrm{~mm}$ overall thickness and imaged to produce a standard high-resolution bubble thick-section (see also Supplemental Fig. S1). Following imaging, the same section was then thinned to $\sim 0.5 \mathrm{~mm}$ for thin-section analysis.

Post-processing of the bubble imagery (optimizing and error-checking) to obtain data on bubble elongation followed Fegyveresi and others $(2011 ; 2016)$. Principal measurements were made of all bubble sizes and shapes using the Fovea Pro ${ }^{\mathrm{TM}}$ imaging software plug-in for Photoshop ${ }^{\mathrm{TM}}$ (Russ, 2010). Analyses especially focused on obtaining quantitatively accurate measures of the extent and direction of bubble elongation, by measuring the moment angle and maximum chord of each bubble as described below. We achieved this through a new four-step process to visually clean, binarize, and color-label each bubble in the section (Fig. 1). Bubbles are treated as 2-D features in the plane of the section.

Moment-angle $(\psi)$ as used here is the angle of the axis (measured counterclockwise from the horizontal) about which the pixels in the feature (bubble) have the smallest moment. For an ellipse, this is the angle of the long axis relative to horizontal, ranging from $0^{\circ}$ to $180^{\circ}$. As implemented in the Fovea Pro ${ }^{\mathrm{TM}}$ software, this measurement has a builtin systematic error of $\sim \pm 3 \%$ due to the effects of pixelization (Russ, 2010). The maximum chord as defined here is the longest single-pixel, straight-line path across each bubble; for an ellipse, this is the length of the major axis. We note that only the numerical moment angle values were used in our calculations; maximum chords are drawn on each bubble simply to aid in visualization. For visualization in
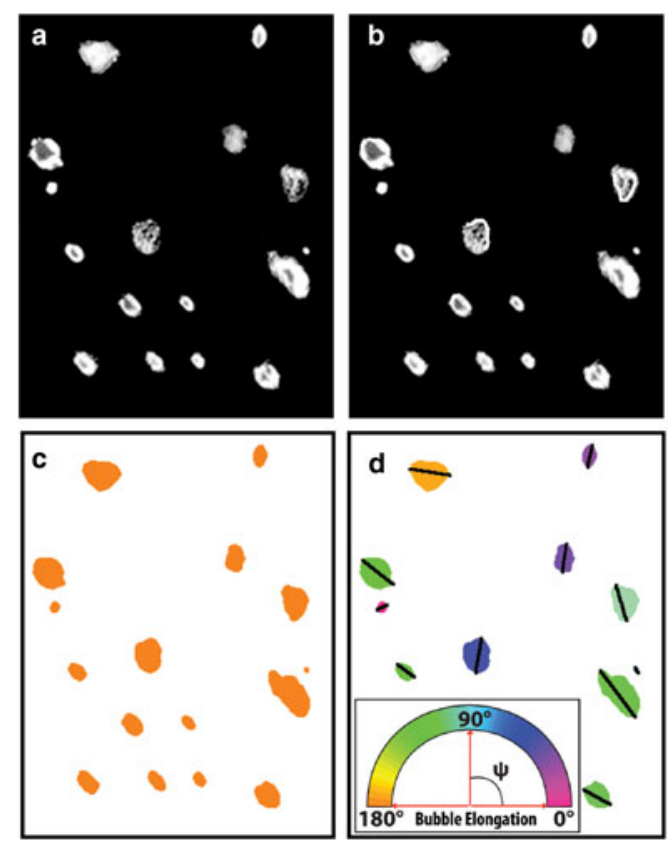

Fig. 1. Four-step process used to clean, colorize and label the VHS580 bubble thick-section sample, shown here for a sub-section of the larger sample. In this example, the raw bubble image (a) was first manually cleaned (b), then binarized (c) and finally colored based on each bubble's moment angle $(\psi)(\mathrm{d})$. Additional 3 pixelwide chord lines are drawn over each bubble for ease of angle identification.

figures (e.g., Fig. 1), bubbles were color-coded based on their moment angle.

We tested the moment-angle measurements by generating artificial 'test bubbles', placing them at various known angles in a synthetic image and then analyzing (Fegyveresi, 2015). We also duplicated the images of four different bubbles of varying elongations and irregularity from the VHS-580 image (see e.g., Supplemental Fig. S2-c), rotated each about its geometric center at $5^{\circ}$ increments from $0^{\circ}$ to $90^{\circ}$ and analyzed the resulting images. The overall error of $0.75^{\circ} \pm 0.35^{\circ}$ is too small to plot legibly in subsequent figures. Experiments with ellipses plotted at exactly known angles confirm the ability of our analyses to measure orientations with very small errors. Once the technique was successfully validated using test bubbles, the entire prepared bubble image from the VHS-580 sample was cleaned, binarized, colored and labeled based on the bubble orientations, using the fourstep process as previously noted. In total, 5245 bubbles were identified in the sample.

We focus here on 'intra-grain' bubbles to study deformation within grains and exclude those 'inter-grain' bubbles touching grain boundaries. We identified and eliminated intergrain bubbles using the grain-boundary tracing (or mesh), which is normally created during thin-section analysis and is discussed in the following sections. Future analyses of the intergrain bubbles may be of considerable interest in answering questions related to grain-boundary sliding, but because of the likely complicating effects of processes including grain-boundary migration, we defer such analyses.

Thin-section preparation for grain analysis

Following the digital imaging and processing of the bubble thick-section, the sample was microtomed to a thickness of 


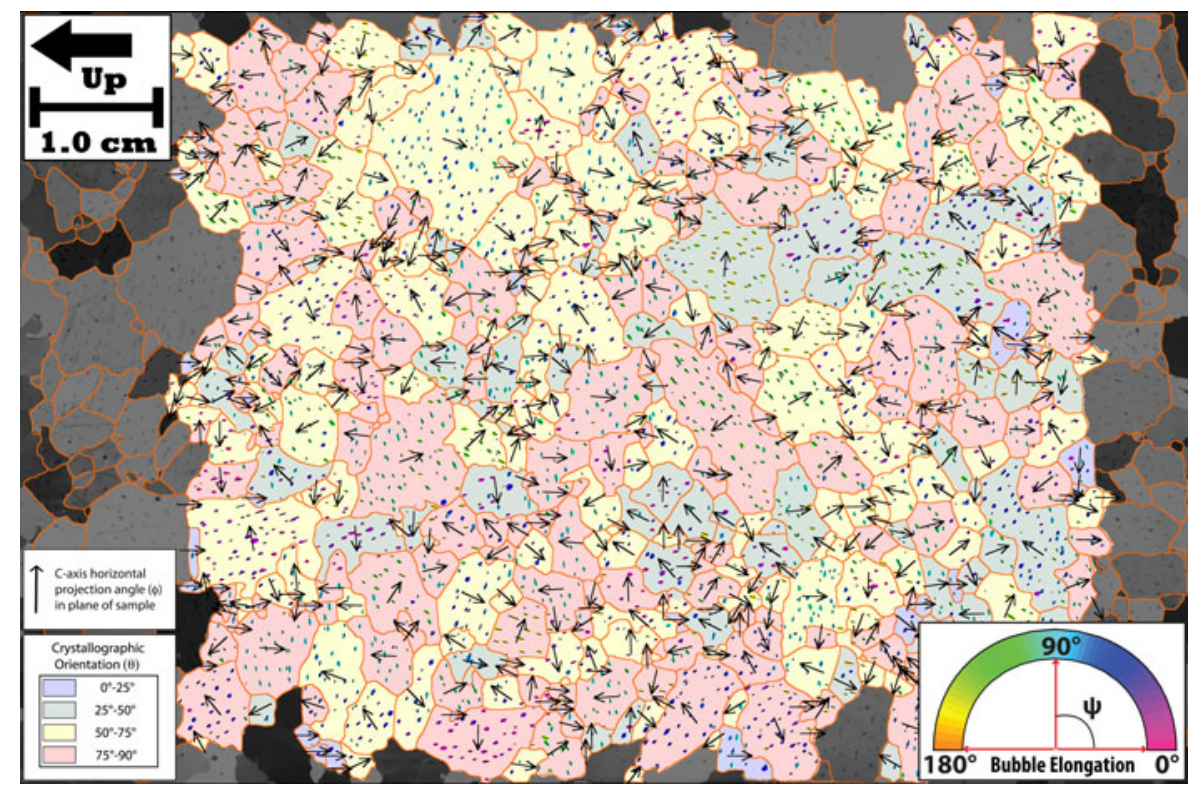

Fig. 2. Hybrid grain-bubble mesh map and c-axis overlay showing 474 measured grains and all measured intra-grain bubbles from the VHS580 sample, colored based on the orientation of the bubble moment angle $(\psi)$. Black arrows indicate horizontal projection angle $(\phi)$ in plane of sample for each grain, and grain colors indicate theta $(\theta)$ angle of each grain. A value of $\theta=90^{\circ}$ indicates a c-axis lying in, or parallel to the plane of the sample. The ice flow direction at WAIS Divide for this sample is estimated to be approximately out of the plane of the section $\left( \pm 5^{\circ}\right)$. Stratigraphic up-core is to the left as indicated.

$\sim 0.5 \mathrm{~mm}$ and digitally imaged under the cross-polarized transmitted light, following the procedures described in Fitzpatrick and others (2014) (Supplemental Fig. S3). Because thin-section microtoming removes most of the thickness and many of the bubbles, we confirmed the high quality of the bubble images before proceeding.

Mean grain size is much larger than the thickness lost in this microtoming, and visual inspection shows, as expected, that the bubble section and thin section sample essentially the same ice. Similar to the bubble thick-section, imaging of overlapping sub-areas was followed by compositing smaller sub-sections. Additional analyses produced a grainboundary mesh with over 700 individual grains (Fitzpatrick and others, 2014).

\section{Grain-mesh overlay and bubble reduction}

The final grain-boundary mesh was captured and saved as an independent layer within the Photoshop ${ }^{\mathrm{TM}}$ imaging software. This layered mesh was then combined with the highresolution bubble image from the previously processed bubble thick-section. With these two parent layers merged, bubbles were separated into intergrain and intragrain sublayers based on their location. Bubbles were identified as intergrain if any part of the bubble was on or touching the identified grain-boundary mesh. Because the grain mesh was set to a width of 5 pixels, and binarized bubbles were also represented by pixels, some intragrain bubbles may have been categorized as touching grain boundaries. We obtained sufficient intragrain bubbles through this approach for robust analyses, so we did not attempt to identify any misclassified bubbles. Subsequent studies addressing differences in deformation within a grain might do so, however.

Using this classification, we obtained 3943 intragrain and 1302 intergrain bubbles. The 5245 bubbles produced two finalized hybrid grain-bubble mesh maps (see also Supplemental Figs. S4, S5), with 3943 total intragrain bubbles, and 1302 intergrain bubbles, respectively. As a final step for display purposes, using only the identified hybrid grain-bubble mesh map, all intragrain bubbles were color-coded based on their moment angle $(\psi)$ using Fovea Pro $^{\mathrm{TM}}$ (see Fig. 2). Maximum chords were also drawn for ease of identification, and to help us in visually doublechecking the fidelity of the analyses.

\section{C-axis overlay and conventions}

Following digital imagery, c-axis orientations were measured using the automatic c-axis analyzer now housed at Penn State and formerly housed at the National Science Foundation Ice Core Facility (NSF-ICF) operated by the US Geological Survey in Denver, Colorado, with scientific management by the University of New Hampshire (Fitzpatrick and others, 2014; Wilen, 2000; Hansen and Wilen, 2002). The $c$-axis analyzer returns theta $(\theta)$, the polar angle and phi $(\phi)$, the azimuthal angle, for specific grains using a suite of images taken with a variety of sample and polarizer orientations. These images have a lower resolution than, and a different spatial registration with, those used to determine the grain boundary mesh as discussed above. To ensure that the $c$-axis orientations were in correct correspondence with the grains identified and numbered in the grain-boundary mesh, we developed a linear coordinate transformation (scaling, rotation and translation) that mapped the center-of-mass coordinates for each grain in the mesh (as determined with Fovea Pro ${ }^{\mathrm{TM}}$ ) to the center of the same grain in the $c$-axis analyzer image coordinates. A $3 \times 3$-pixel region centered on these coordinates was then used to analyze the c-axis orientation for that grain using the corresponding numbering from the high-resolution imagery. The theta angle $(\theta)$ varies from $0^{\circ}$ for a $c$-axis perpendicular to the plane of section, to $90^{\circ}$ for a $c$-axis in the plane of section. The phi angle $(\phi)$ is measured counterclockwise in the plane of section, with $0^{\circ}$ indicating a $\mathrm{C}$-axis pointing stratigraphically down-core, and $180^{\circ}$ pointing stratigraphically up-core (see Supplemental Figs. S6, S7). 


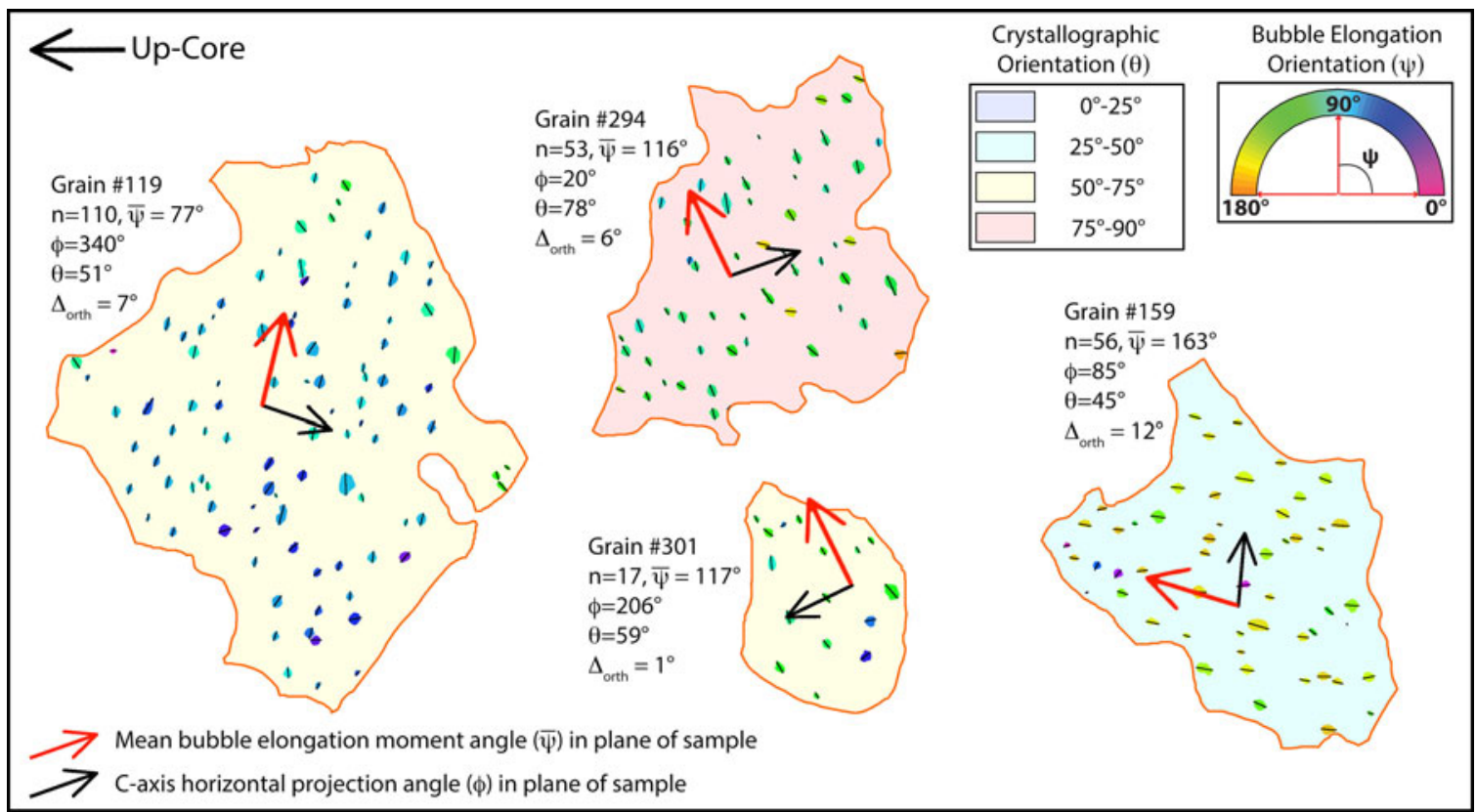

Fig. 3. Four individually measured grains from Figure 2. Black arrows indicate c-axis horizontal rotation angle $(\phi)$, and red arrows the calculated mean elongation-orientation moment angle $(\bar{\psi})$ for all bubbles within a grain. Total bubble counts for each bubble are given as $(n)$. Visual inspection shows the approximate orthogonal relationship between $(\phi)$ and $(\bar{\psi})$ within each grain, indicating that average bubble elongation is along the basal plane of the grains. Here, $\left(\Delta_{\text {orth }}\right)$ represents the angle difference between the plane normal to $(\phi)$ and the elongation-orientation moment angle $(\bar{\psi})$; or precisely how many degrees from orthogonal $\left(90^{\circ}\right)$ the relationship is. Stratigraphic up-core is to the left as indicated.

The automatic c-axis analyzer has a practical sample-size limit of $\sim 6 \mathrm{~cm} \times 6 \mathrm{~cm}$ (Wilen, 2000; Hansen and Wilen, 2002; Fitzpatrick and others, 2014), slightly smaller than the original VHS-580 thin section; hence, a small number of grains along the edges of the image were not analyzed. Additionally, owing to a slightly coarser resolution and other limitations of the technique, the analyzer may occasionally fail to return a c-axis orientation from a grain identified in the high-resolution imagery. For example, this may occur for a grain boundary nearly parallel to the section surface, or for very small grains $(<12$ total pixels). Statistically, the loss of very small grains in the analysis is not significant due to their inherent lack of bubbles. Of the 700 grains originally mapped in the sample, 474 were successfully measured. A c-axis overlay was created using the grain-boundary mesh. In addition to color-coded bubble elongation data as noted above, Figure 2 also shows this final $C$-axis overlay with all of the measured grains colored, and others not analyzed in greyscale. Black arrows representing $c$-axis phi $(\phi)$ angles and color-coding for $C$-axis theta $(\theta)$ angles are also shown for each measured grain.

\section{Individual grain-bubble processing}

To compare bubble orientations to the $c$-axis orientation for a single grain, the boundary of that single grain was first selected using edge-detection tools in the Photoshop ${ }^{\mathrm{TM}}$ software. The grain and bubble layers for this grain were then selected together, copied, merged and duplicated into a new layer. All of the intragrain bubbles in this new layer were then counted ( $n=$ bubble count) and processed independently using the built-in Fovea Pro ${ }^{\mathrm{TM}}$ measurement utilities, producing a table containing all shape and moment angle data (see also Fegyveresi and others, 2011, 2016). This process was repeated for each of the 474 grains with full data (examples are shown in Fig. 3). Bubble elongation was quantified using the 'Aspect Ratio' metric as returned by the software, which is a direct comparison of long-Feret axis divided by short-Feret-axis (or simply length (L) divided by breadth (B)). Fovea Pro $^{\text {TM }}$ defines the Feret-axes as caliper dimensions that represent the longest straight-line distance between two points along the shortest- and longestaxes, respectively (Russ, 2010). Effects of pixelation are small, and similar across bubbles because of the narrow size distribution. With these processed bubble characterization data, we were then able to compare the moment angle $(\psi)$ for each of the 2377 bubbles to the crystallographic orientation of its parent grain by calculating the acute angle between the bubble long-axis and the c-axis horizontal rotation angle $(\phi)$.

\section{RESULTS}

We first report on several tests to determine whether the bubble elongations primarily record strain rates. We consider orientations of bubble elongation relative to basal planes, the magnitude of elongation relative to expected values based on physical understanding and dependence of elongation on bubble size. All of these yield results consistent with control of bubble elongation by deformation of the surrounding ice, so the bubbles can be used as strain indicators. We then show that elongation, and thus deformation, depends on $c$-axis orientation and grain size.

\section{Tests that bubble elongations record ice deformation}

The sample analyzed here is from $\sim 580 \mathrm{~m}$ depth, in the upper $20 \%$ of the ice sheet, where basal shear is minor and vertical compression dominant (e.g., Conway and others, 2005; Cuffey and Paterson, 2010). Measured modern 


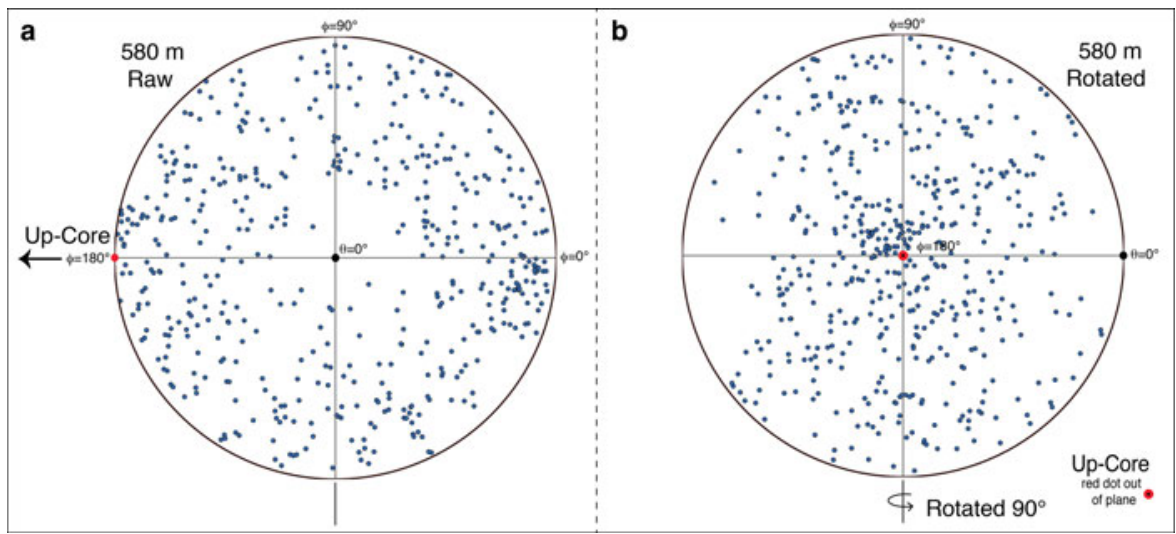

Fig. 4. Schmidt plot of $\mathrm{c}$-axis data from 474 measured grains in VHS-580 sample. Plot (a) shows the raw data following the fabric convention from Supplemental Fig. S6 with stratigraphic up-core to the left indicated with black arrow and red dot. Plot (b) shows the data rotated to represent a view down-core. Here, stratigraphic up-core is coming out of the page (red dot). In this view, the effects of grain rotation are apparent in the weak clustering toward the center, as described in Fitzpatrick and others (2014)

surface velocities of $\sim 3 \mathrm{~m} \mathrm{a}^{-1}$, decreasing up-glacier, indicate along-flow extension and weak transverse compression (i.e., flow-lines converge as flow accelerates along-flow and layers thin by $\sim 7 \times 10^{-5} \mathrm{a}^{-1}$ ) (Conway and Rasmussen, 2009; Buizert and others, 2015). C-axis fabrics near the base of the firn $(\sim 75 \mathrm{~m})$ are nearly random with slight vertical clustering; with increasing depth, the c-axes rotate towards a vertical plane transverse to flow, with the strongest clustering near the vertical axis (Fitzpatrick and others, 2014). The Schmidt plot of the $c$-axes of the 474 grains analyzed from the VHS-580 sample (Fig. 4) falls along the trend identified by Fitzpatrick and others (2014), with relatively weak but clear vertical clustering. The orientation of the ice core was not independently measured when collected, but an understanding of the relation between $c$-axis fabrics and ice flow, together with the measured $c$-axis fabric of this section, indicate that the plane of section is approximately orthogonal to ice flow (Fitzpatrick and others, 2014).

Bubble elongations (measured as aspect ratios, L/B) in the VHS-580 sample were generally small $(<2.0)$, as expected (Alley and Fitzpatrick, 1999). A histogram of the aspect ratios of all 3943 intragrain bubbles shows a right-skewed distribution with a mode of 1.3 and a positive skew of 2.8 (Fig. 5). The long tail of the distribution may indicate the formation of stress-release cracks as described in Fegyveresi and others (2016). To account for this, and to ensure no subsequent measurement complications, grains containing bubbles with easily identifiable stress-release cracks were excluded from further analyses. In addition, to improve statistics and minimize the influence of outliers, only grains with five or more included bubbles $(n \geq 5)$ were used. Of the total 474 measured grains, 148 met the threshold criteria of $n \geq 5$, and a lack of identifiable stress-release cracks. These 148 grains contain 2377 of the original 3943 intragrain bubbles. The Schmidt plot for the smaller 148-grain sample sub-set is shown in Supplemental Fig. S8, where $\left(H_{S}\right)$ denotes 'hybrid sample sub-set'. The $C$-axis fabric for this sub-set $\left(H_{S}\right)$ matches the fabric for the full dataset closely (i.e., Fig. 4).

The comparison between the moment angles $(\psi)$ for each of the 2377 bubbles and the crystallographic orientation of their parent grains is shown in Figure 6 and Supplemental Fig. S9. Additionally, the mean of the moment-angles of all bubbles in each grain was similarly compared with the grain orientation. The results show that bubbles in a grain are strongly aligned with or near the basal plane of that grain. A linear regression $\left(R^{2}=0.96\right)$ shows a slight offset $\left(\sim 5^{\circ}-7^{\circ}\right)$, consistent with the expectation noted by Gay (1968), that bubbles initially elongate at an angle to the basal shear plane and then the bubble long axis rotates toward the shear plane without fully reaching it. An analysis of all 2377 individual bubbles revealed that $\sim 75 \%(1771$ bubbles) were elongated within $20^{\circ}$ of the basal plane. The right-skewed (skewness of 1.9) distribution of angle differences between all bubble elongation-orientations and their respective parent grain basal planes (shown in Fig. 6 histogram inset) further yields a mode of $\sim 3^{\circ}$, a median of $\sim 9.7^{\circ}$, a $1 \sigma$ Std dev. of $\sim 18.7^{\circ}$, and an average of $\sim 16.6^{\circ}$.

As noted previously, the bubble 'elongations' measured here are the elongations of normal projections of bubbles onto the plane of section, and represent the true elongation only for bubbles elongated in the plane of section. Our observational technique did not allow us to rotate bubbles to measure their full elongation. To partially overcome this difficulty, we note that grain deformation causing bubble elongation is expected to increase with the Schmid factor (S), and that under the near-vertical compression of the WAIS Divide site, this would cause bubbles in grains with $c$-axes close to the plane of section to exhibit their true elongation. We selected a subset of 86 such grains $\left(H_{S \_P L A N A R}\right)$ with c-axes within $25^{\circ}$ of the plane of section $\left(\theta \geq \sim 65^{\circ}\right)$; this value was chosen to give a large enough sample while not deviating too much from the plane of section. As expected, the bubble elongations in this subset of grains trend slightly larger $($ median $=1.45$, mean $=1.55)$ than for the full set of bubbles (see also Supplemental Fig. S10).

\section{DISCUSSION}

We next place these results in context and explore possible implications. Following a short summary of key background assumptions, we show that if these background assumptions apply, the measured elongations are consistent with the particular assumptions underlying the use of bubble elongation as a strain indicator, with deformation balanced by diffusive restoration and with larger bubbles elongating more rapidly. Following the generally positive results from these methodological tests, we use the measured bubble elongations to 


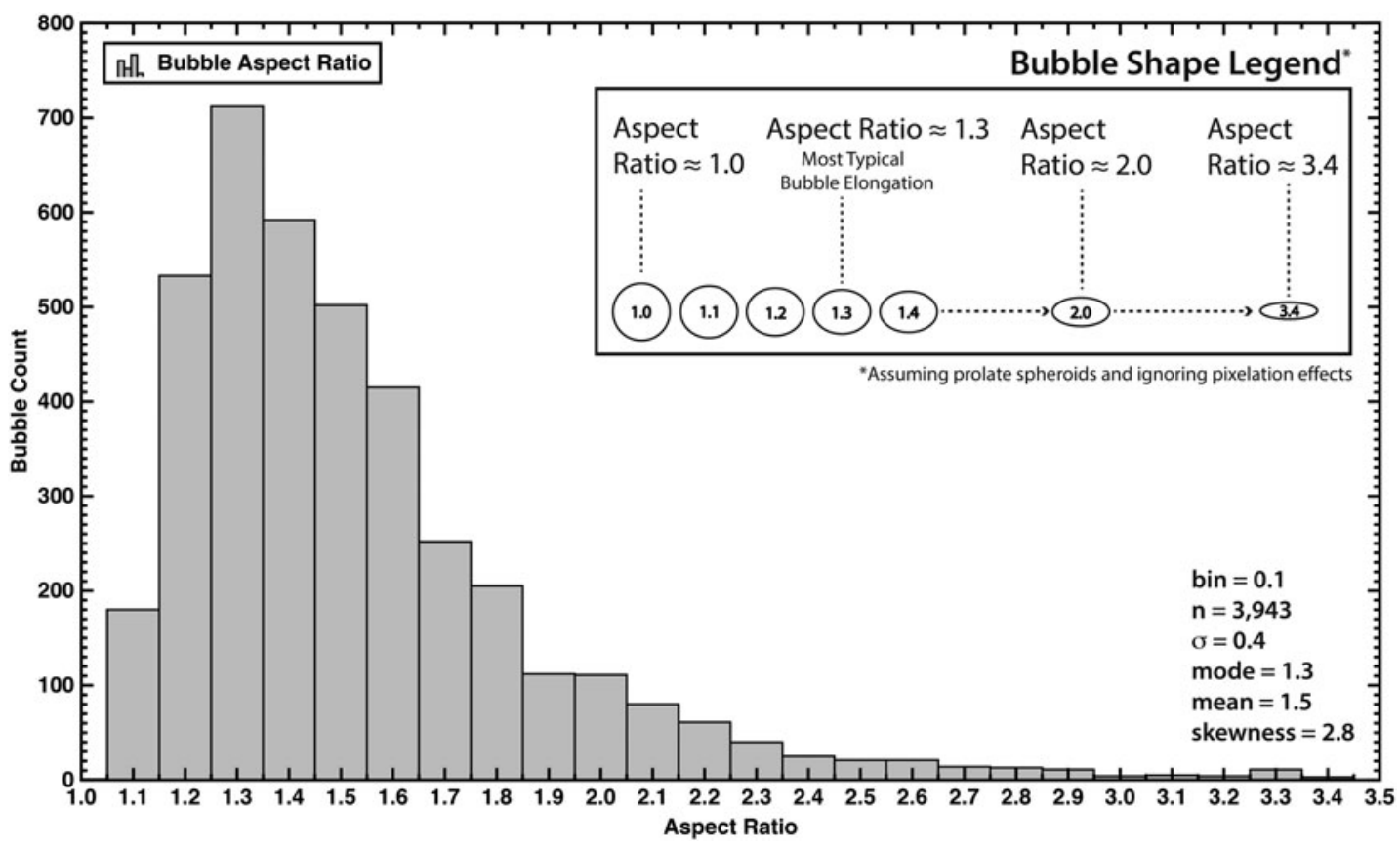

Fig. 5. Histogram of measured elongation (aspect ratio, L/B) for all 3943 intra-grain bubbles $(n)$; bin width $=0.1$. Distribution is a classic positive, right-skewed result, heavily clustered towards lower values. The mode is $\sim 1.3$. The legend shows visual representations of aspect ratios assuming all bubbles appeared as ellipses in the bubble section.

conduct tentative hypothesis-testing for grain-scale deformation by examining the dependence of elongation on $c$-axis orientation and size of the enclosing grain.

\section{Magnitude of bubble elongation}

In analyzing bubble elongation, we assume that the current configuration integrates the cumulative deformation for the entire history of the ice, the same assumption used in successful model simulations of the observed c-axis fabrics in ice cores (e.g., Alley, 1988; Duval and Montagnat, 2002).

We note that nucleation of new grains together with formation of subgrain boundaries has been observed in samples from other cores, peaking in deep firn (e.g., Kipfstuhl and others, 2006; 2009; Weikusat and others, 2009; Faria and others, 2014) and likely related to the very high firn-densification stresses (e.g., Alley, 1987). These stresses typically peak near 5-6 bars before pressurization of

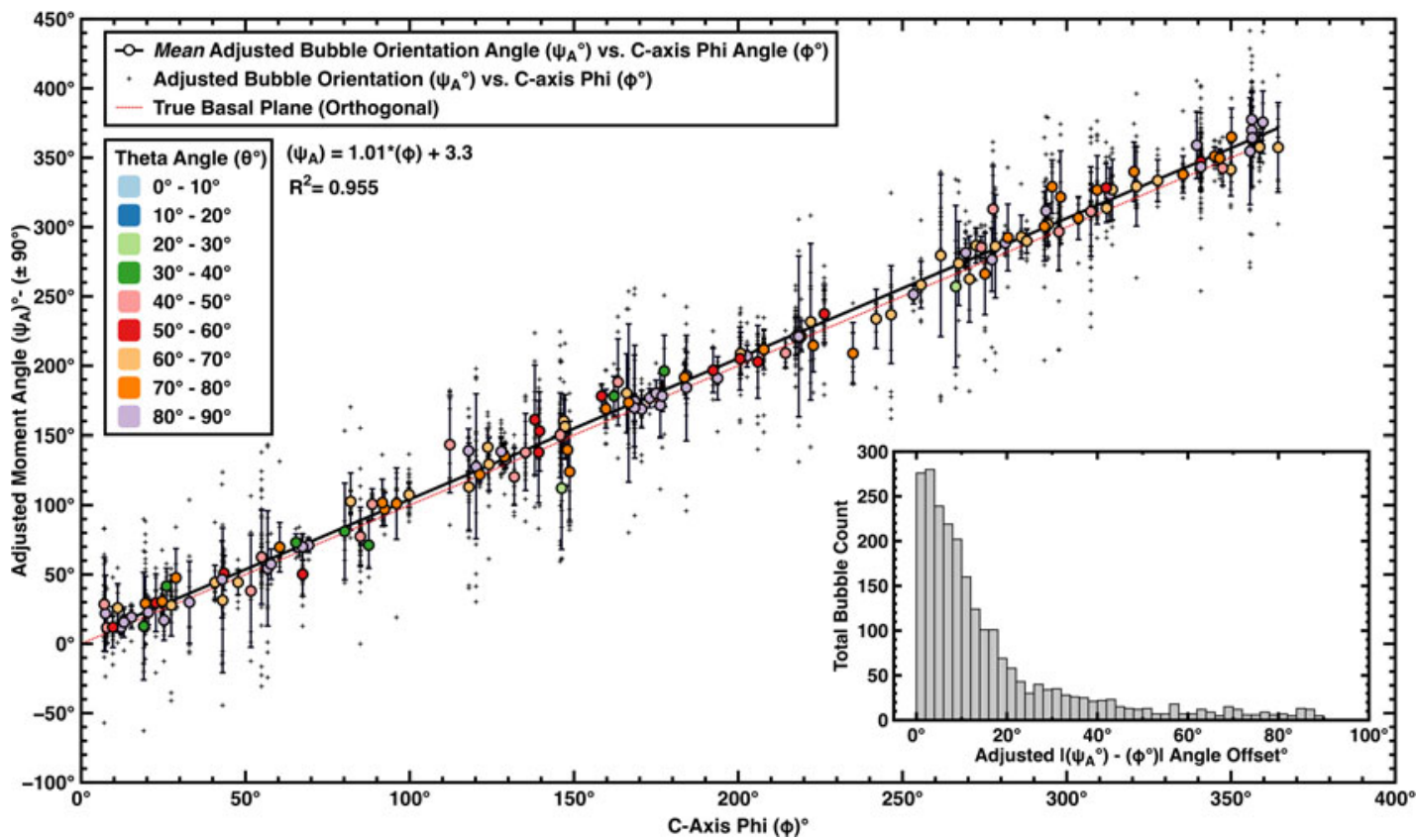

Fig. 6. Plot of adjusted bubble-orientation angle $\left(\psi_{\mathrm{A}}\right)$ vs C-axis horizontal rotation angle $(\phi)$ for 148 measured sample sub-set $\left(H_{S}\right)$ of $V H S$-580. Small data points indicate all 2377 individual bubbles measured; larger, colored data points indicate average values per measured grain. Fill colors reflect associated theta $(\theta)$ values for each parent grain. The error bars are measured Std dev. $(1 \sigma)$ for all bubbles within each grain. Linear regression (black solid line) yields an $R^{2}$ of $\sim 0.955$, and falls slightly above the line indicating a true basal plane correlation (red dotted line). Histogram inset (bin width $=2^{\circ}$ ) shows the right-skewed distribution of the $\left(\psi_{\mathrm{A}^{-}} \phi\right)$ offset angles for each bubble (shown as absolute values). Effects of pixelization and cut-bubbles were ignored. (see Supplemental Fig. S9 for the raw-data equivalent plot). 

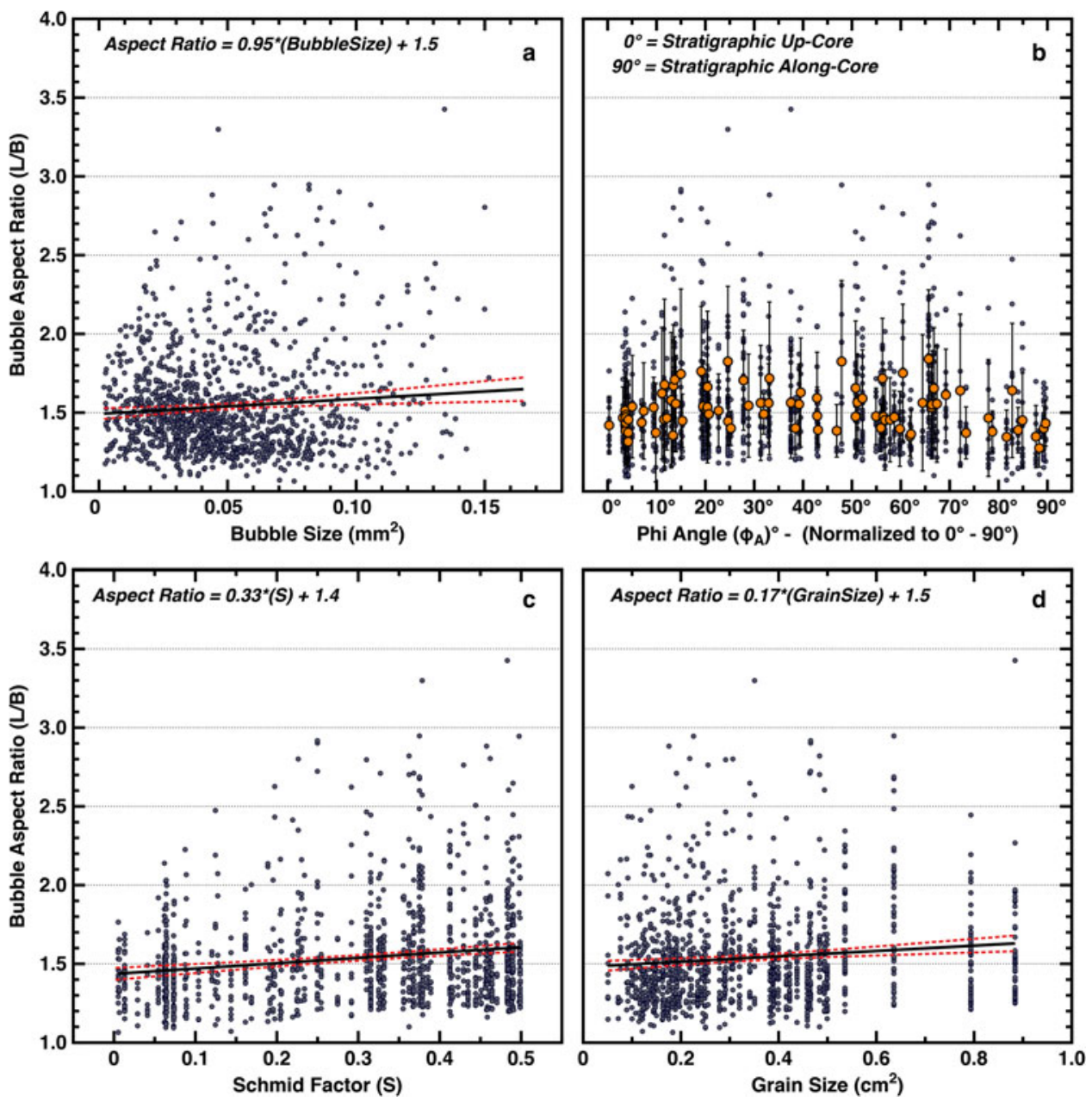

Fig. 7. Data plotted from 86 grains identified as being within $25^{\circ}$ of the visual plane $\left(H_{S \_P L A N A R}\right)$ of the sample $\left(\theta \geq 65^{\circ}\right)$. Plot (a) shows bubble elongation (aspect ratio) distributions plotted against their respective size (pixel area $-\mathrm{mm}^{2}$ ), with a positive increasing linear trend (slope of $0.95 \pm 0.32$ ). Plot (b) shows bubble elongation distributions plotted against their respective adjusted phi $\left(\phi_{\mathrm{A}}\right)$ angles (normalized to adjusted values between $0^{\circ}$ and $90^{\circ}$, with $0^{\circ}$ equating to stratigraphic up-core as indicated). Minor data points (blue) indicate individually measured bubbles, while major data points (orange) indicate mean values. The error bars are measured Std dev. (1 $\sigma$ ) for all bubbles within each grain. Plot (c) shows bubble elongation distributions plotted against their respective Schmid factor (S), with a positive increasing linear trend (slope of $0.33 \pm 0.06)$. Plot $(\mathrm{d})$ shows bubble elongation distributions plotted against their respective parent grain size (pixel area $\left.-\mathrm{cm}^{2}\right)$ with a positive increasing linear trend (slope of $0.17 \pm 0.04$ ). Dashed red lines indicate 95\% confidence bands. See Supplemental for additional statistics.

bubbles. However, as stated by Faria and others (2014, section 5.2, p. 38) for the relevant depths: Nucleation is not predominant in polar ice...'. Strengthening of subgrain boundaries until they are classified as grain boundaries does divide grains with little effect on c-axis fabrics (e.g., Alley and others, 1995). In our case with the WDC06A core, while this subgrain-strengthening behavior is clearly evident in ice from greater depths than our sample, it is not prominent near or above our sample (Fitzpatrick and others, 2014). Instead, our sample occurs within a trend of increasing grain size and smoothly tightening $c$-axis fabric with increasing age and depth.

The following simple calculation shows that the magnitude of our measured elongations is consistent with this assumption of long-lived grains, and with the expectation that bubbles are elongated by cumulative deformation but returned toward spherical by diffusion because somewhat more strain has occurred in most grains than is recorded in the bubble shapes. The sample from $\sim 580 \mathrm{~m}$ has an approximate age of 2360 years bf 1950 (Sigl and others, 2016); removing time in firn (175 years), and adding time from
1950 to core recovery (67 years), gives a total age of $\sim 2252$ years. The vertical strain rate at WAIS Divide is $\sim 7 \times 10^{-5} \mathrm{a}^{-1}$ (modern accumulation rate of $\sim 0.22 \mathrm{~m}_{\text {ice }} \mathrm{a}^{-1}$, divided by total ice thickness of $\sim 3450 \mathrm{~m}$ ) (WAIS Divide Project Members, 2013; Fudge and others, 2016), so thinning of $\sim 16 \%$ has occurred in the ice. Because bubbles are estimated to elongate $\sim 5 / 3$ as fast as the surrounding ice, $16 \%$ layer thinning assuming pure shear would convert an initially spherical bubble of unit diameter to a length of 1.27 , and width of $1 / 1.27$ and thus an elongation of $1.27 /(1 / 1.27)=$ 1.6. The modal elongation is $\sim 1.3$ in the maximum-strain subset of grains, suggesting that diffusion is active in restoring bubbles toward spherical (see Alley and Fitzpatrick, 1999, Gay, 1968).

As an additional check, we note that Alley and Fitzpatrick (1999) found from physical modeling and confirmed by observations that larger bubbles should elongate more rapidly. Thus, if bubbles are behaving as expected in recording strain, larger bubbles measured within our VHS-580 sample should reveal greater elongation. We plot bubble elongation (aspect ratio) against bubble size for all bubbles 
within the $\left(H_{S}\right.$ PLANAR $)$ subset, and find that larger bubbles do exhibit slightly greater elongation (Fig. 7a). A $t$ test on the significance of the slope is positive (with $P<0.05$ ); however, there is much variance that is not described in this significant relation, which we discuss further below (see also Supplemental for additional statistics).

\section{Grain-scale deformation from bubble elongation}

To test the hypothesis that grain-scale deformation increases with the resolved shear stress on the basal plane, we plot (Fig. $7 b$ ) the bubble elongations for the subset of grains expected to show maximum elongation (HSPLANAR), against their $c$-axis orientation phi $(\phi)$ angles $\left(\phi=0^{\circ}\right.$ upcore to $90^{\circ}$ along-core). If deformation of the grains, and therefore the bubbles, is proportional to the Schmid factor $(\mathrm{S})$ as hypothesized in some models, the resulting plot should yield minimum elongation at $0^{\circ}$ and $90^{\circ}$, with a maximum near $45^{\circ}$. The data show fewer highly elongated bubbles near $0^{\circ}$ and $90^{\circ}$ but with little trend for intermediate angles. In Figure 7c, these data are replotted against Schmid factor (S) calculated assuming vertical compression and show that elongation does increase with $S$, although with considerable variability. A minimum is apparent at 0 (equating to phi angles near $0^{\circ}$ and $90^{\circ}$ ), and a more distinct maximum/distribution is also now present at Schmid factors near 0.50 (equating to phi angles near $45^{\circ}$ ). The trend is statistically significant; the slope of the regression line of bubble elongation against $S$ is $0.33 \pm 0.06$, positive with $>95 \%$ confidence, based on a $t$ test $(P<0.05)$. The formal $t$ test likely overestimates the confidence in the result, in part from the skewed nature of the distribution of elongations (that in turn arises in part from the definition of elongation as being $\geq 1$ ), but we have looked at the data in various ways and with various statistical treatments, and find it likely that there is some dependence of elongation on Schmid factor (S). We note that the regression line, or any other relation we have tested, explains only a small fraction of the variance and thus does not provide a full model of the grain-scale deformation.

Next, to test the hypothesis that larger grains exhibit greater deformation, the bubble elongations for all grains and for the $\left(H_{\text {S_PLANAR }}\right)$ subset are plotted against grain size in Figure $7 \mathrm{~d}$. As before, the data exhibit much variability, but with a positive trend indicating faster deformation for larger grains; the slope of the regression line of bubble elongation against grain size is $0.17 \pm 0.04$, positive with $>95 \%$ confidence, based on a $t$ test $(P<0.05)$. This result again leaves much variance unexplained. The unexplained variance in the linear relations here may in part arise from a tendency toward Reuss (1929) behavior, with softer grains supporting less stress and deforming similarly to their neighbors, but other explanations may apply.

Challenges exist both in observing and interpreting the elongations, as discussed more below, but the preliminary work here shows that there are patterns in bubble elongation reflecting grain deformation. In particular, the increase in elongation with Schmid factor (S) suggests that the strain rate in a grain increases with the resolved shear stress on its basal plane, but a large amount of variance that is not explained by this model (i.e. low $R^{2}$ values) suggests that a complete model of ice deformation will involve additional considerations.

\section{Limitations}

We are acutely aware of limitations in this study. We have examined only one section, without truly 3-D data on bubble elongations. Application of other techniques, or of this technique to mutually perpendicular sections from the same depth, as well as to corresponding sections from additional ice core sites (e.g. the new SPICEcore from the South Pole), would improve characterization and help demonstrate that we are not observing some unknown peculiarity of our site, or some unknown artifact from the particular recovery and processing history of this core (Casey and others, 2014; Fegyveresi, 2015). We chose our sample depth to be great enough for notable deformation to have occurred but not so deep as to fall within the upper part of the 'brittle ice' zone (Souney and others, 2014), and to be above the depth of major grain subdivision or dominant nucleation of new grains (see above). We inspected the bubbles carefully in an attempt to avoid any possible effects of stress-relief cracks affecting bubble shape (see e.g. Kipfstuhl and others, 2001; Pauer and others, 2000), but we cannot guarantee that every crack was identified and eliminated. Preparation and imaging of samples in the field immediately following the recovery of ice cores would simplify interpretations, because stress-release cracks are initially very thin and readily removable from bubble shapes, but subsequent diffusion might widen the cracks and affect bubble shapes.

As discussed by Alley and Fitzpatrick (1999), quantitative interpretation is complicated by the fact that available solutions relating bubble elongation to the surrounding flow are for linear-viscous deformation, but ice is expected to creep proportional to a power of the stress greater than one. This is complicated further because the few available data are broadly consistent with linear behavior (Nakawo and Wakahama, 1981). A completely proper treatment of bubble deformation is likely to prove difficult, so we also assume here the simple approach for the elongation of linear-viscous inclusions (bubbles) in a linear-viscous matrix (see also Gay, 1968).

Many bubbles will switch grains owing to grain growth (e.g., Alley and others, 1986a; 1986b), changing the direction and rate of elongation, even as those grains are rotating, thereby affecting their Schmid factor and their tendency to deform. Numerical modeling of bubble evolution coupled to grain growth and deformation will be required to quantify the effects of these processes, matched to a depth-progression of observations beginning near the base of the firn (e.g. Steinbach and others, 2016). Note, however, that the most-recent deformation is most important in controlling bubble elongation, and notable elongation would be generated over times shorter than the age of the ice (Alley and Fitzpatrick, 1999).

\section{CONCLUSIONS}

In light of the considerations above, we do not draw strong conclusions here. We hope to conduct future research to reduce uncertainties, but we find the preliminary results to be sufficiently interesting that we are publishing them in hope of stimulating other researchers to extend this work. Our tests suggest that the magnitude and direction of bubble elongation are controlled by the balance between deformation in the ice and diffusion restoring bubbles 
toward spherical, such that bubbles are elongated close to (but not exactly on) basal planes, the magnitude of elongation is consistent with physical expectations, and larger bubbles show greater elongation (Alley and Fitzpatrick, 1999). In turn, this suggests that the bubbles are serving as strain indicators. If so, then bubble shapes may offer the best opportunity to characterize grain-scale deformation under in situ ice-sheet conditions.

Interpreting the bubbles as strain indicators, we find that there are significant patterns in bubble elongation reflecting grain deformation such that deformation increases with the resolved shear stress on the basal planes arising from the far-field stress state. These relations leave much variance unexplained, however, with elongated bubbles observed in almost all grains. One possible, although nonunique, interpretation is that the grain-scale interactions create a strongly heterogeneous stress state, and when combined with the extreme anisotropy of ice, all grains ultimately deform along their basal planes, with significantly slower deformation only for those grains in which the resolved shear stress on the basal plane is very small.

We also find that larger grains contain more-elongated bubbles. Because such grains have generally become larger by outward grain-boundary migration, incorporating bubbles with the associated switch in deformation pattern, one might expect larger grains to contain less-elongated bubbles. The inference is that larger grains deform more rapidly. In turn, this suggests that the inferred lower viscosity of finer-grained ice arises from grain-boundary processes rather than intragranular slip (Cuffey and others, 2000; Goldsby and Kohlstedt, 2001), a hypothesis that we believe merits additional testing including targeted modeling of coupled grain growth and deformation.

More broadly, we feel that this study, while limited in scope, has larger potential implications for the future development of more complete models of ice deformation.

\section{ACKNOWLEDGEMENTS}

We acknowledge the following funding sources for support of this work: US National Science Foundation Division of Polar Programs grants 0539578, 1043528 and 1542778. We also acknowledge Eric D. Cravens, and the staff of the National Science Foundation Ice Core Facility (NSF-ICF) in Denver, Colorado, as well as the WAIS Divide Science Coordination Office at the University of New Hampshire and the Ice Drilling Design and Operations group at the University of Wisconsin. We thank numerous colleagues involved with the WAIS Divide project, especially Kendrick Taylor, Mark Twickler and Joseph Souney. We thank Bess Koffman, Gifford Wong, Richard Nunn and Anais Orsi for assistance with WAIS Divide sample recovery. We also thank Madeline Nyblade for assistance with the processing and interpretation of the bubble characterization data. Any use of trade, firm, or product names is for descriptive purposes only and does not imply endorsement. Lastly, we thank our reviewers and editor, whose thoughtful suggestions and questions served to significantly clarify and improve this manuscript.

\section{DATA POLICY}

All data presented here are available through the request of the corresponding author, or via download from USAP-DC (https://doi.org/10.15784/601087; Fegyveresi, 2018).

\section{AUTHOR CONTRIBUTIONS}

JJF assisted with thin-section preparation, imagery and analyses. DEV operated the c-axis analyzer and collected the related $c$-axis fabric data. LAW assisted with the overlay and alignment of $c$-axis and digital imagery meshes. JMF prepared and imaged the bubble 'thick-section' and completed the majority of the image processing, analyses and statistics. JMF prepared the manuscript and figures with primary contributions and assistance from RBA.

\section{SUPPLEMENTARY MATERIAL}

The supplementary material for this article can be found at https://doi.org/10.1017/aog.2018.23.

\section{REFERENCES}

Alley RB (1987) Firn densification by grain-boundary sliding: a first model. J. Phys. Colloques, 48(C1), 249-256 (doi: 10.1051/jphyscol:1987135)

Alley RB (1988) Fabrics in polar ice sheets: development and prediction. Science, 240(4851), 493-495 (doi: 10.1126/science. 240.4851.493)

Alley RB (1992) Flow-law hypotheses for ice-sheet modeling. J. Glaciol., 38(129), 245-256 (doi: 10.1017/S0022143000003658)

Alley RB and Bentley CR (1988) Ice-core analysis on the Siple Coast of West Antarctica. Ann. Glaciol., 11, 1-7 (doi: 10.1017/ S0260305500006236)

Alley RB and Fitzpatrick JJ (1999) Conditions for bubble elongation in cold ice-sheet ice. J. Glaciol., 45(149), 147-153 (doi: 10.1017/ S0022143000003129)

Alley RB, Perepezko JH and Bentley CR (1986a) Grain growth in polar ice: I. Theory. J. Glaciol., 32(112), 415-424 (doi: 10.3189/S0022143000012120)

Alley RB, Perepezko JH and Bentley CR (1986b) Grain growth in polar ice: II. Application. J. Glaciol., 32(112), 425-433 (doi: 10.3189/S0022143000012132)

Alley RB, Gow AJ and Meese DA (1995) Mapping c-axis fabrics to study physical processes in ice. J. Glaciol., 41(137), 197-203 (doi: 10.3189/S0022143000017895)

Azuma $\mathrm{N}$ and Higashi A (1985) Formation processes of ice fabric pattern in ice sheets. Ann. Glaciol., 6, 130-134 (doi: 10.1017/ S0260305500010168)

Baker I, Liu F, Jia K, Hu X and Dudley M (1996) Dislocation/Grain Boundary Interactions in Ice Crystals under Creep Conditions. In Mater. Sci. Forum, 207, 581-584. Trans Tech Publications (doi: 10.4028/www.scientific.net/MSF.207-209.581)

Baker I and 5 others (2000) Dynamic observations of dislocation/ grain-boundary interactions in ice. Ann. Glaciol., 31, 236-240 (doi: 10.3189/172756400781820525)

Bouchez JL and Duval P (1982) The fabric of polycrystalline ice deformed in simple shear: experiments in torsion, natural deformation and geometrical interpretation. Texture, Stress Microstruct., 5(3), 171-190 (doi: 10.1155/TSM.5.171)

Budd WF and Jacka TH (1989) A review of ice rheology for ice sheet modelling. Cold Reg. Sci. Technol., 16(2), 107-144 (doi: 10.1016/0165-232X(89)90014-1)

Buizert C and 16 others (2015) The WAIS divide deep ice core WD2014 chronology - part 1: methane synchronization (6831 ka BP) and the gas age-ice age difference. Clim. Past, 11, 153-173 (doi: 10.5194/cp-11-153-2015)

Casey KA and 5 others (2014) The 1500 m South Pole ice core: recovering a 40 ka environmental record. Ann. Glaciol., 55(68), 137146 (doi: 10.3189/2014AoG68A016)

Conway $\mathrm{H}$ and 9 others (2005) Proposed drill site near the RossAmundsen ice divide, West Antarctica. White Paper for the US Ice Core Working Group. 
Conway H and Rasmussen LA (2009) Recent thinning and migration of the Western Divide, central West Antarctica. Geophys. Res. Lett., 36, L12502 (doi: 10.1029/2009GL038072)

Cuffey KM and Paterson WSB (2010) The physics of glaciers, 4th edn. Butterworth-Heinemann, Oxford

Cuffey KM, Thorsteinsson T and Waddington ED (2000) A renewed argument for crystal size control of ice sheet strain rates. J. Geophys. Res., Solid Earth, 105(B12), 27889-27894 (doi: 10.1029/2000JB900270)

Cuffey KM and 8 others (2016) Deglacial temperature history of West Antarctica. Proc. Natl. Acad. Sci. USA, 113(50), 14249 14254 (doi: 10.1073/pnas.1609132113)

Duval P and Montagnat M (2002) Comment on 'superplastic deformation of ice: experimental observations' by D.L. Goldsby and D.L. Kohlstedt. J. Geophys. Res.: Solid Earth, 107(B4), 1-4 (doi: 10.1029/2001JB000946)

Duval P, Ashby M and Anderman I (1983) Rate controlling processes in the creep of polycrystalline ice. J. Phys. Chem., 87(21), 40664074 (doi: 10.1021/j100244a014)

Faria SH, Weikusat I and Azuma N (2014b) The microstructure of polar ice. Part II: state of the art. J. Struct. Geol., 61, 21-49 (doi 10.1016/j.jsg.2013.11.003)

Fegyveresi JM (2015) Physical properties of the West Antarctic Ice Sheet (WAIS) Divide deep core: development, evolution, and interpretation. (PhD thesis, The Pennsylvania State Univ., State College, PA, USA)

Fegyveresi JM (2018) WAIS Divide $580 \mathrm{~m}$ bubble and grain hybrid data. U.S. Antarctic Program (USAP) Data Center. Dataset (doi: 10.15784/601087)

Fegyveresi JM and 7 others (2011) Late-Holocene climate evolution at the WAIS divide site, west Antarctica: bubble number-density estimates. J. Glaciol., 57(204), 629-638 (doi: 10.3189/ $002214311797409677)$

Fegyveresi JM and 7 others (2016) Five millennia of surface temperatures and ice core bubble characteristics from the WAIS Divide deep core, West Antarctica. Paleoceanography, 31(3), 416-433 (doi: 10.1002/2015PA002851)

Fitzpatrick JJ (1994) Preliminary report on the physical and stratigraphic properties of the Taylor Dome ice core. Antarc. J. U.S.A., 29, 84-85

Fitzpatrick JJ and 10 others (2014) Physical properties of the WAIS Divide ice core. J. Glaciol., 60(224), 1181-1198 (doi: 10.3189/ 2014JoG14J100)

Fudge TJ and 8 others (2016) Variable relationship between accumulation and temperature in West Antarctica for the past 31,000 years. Geophys. Res. Lett., 43(8), 3795-3803 (doi: 10.1002/2016GL068356)

Gay NC (1968) Pure shear and simple shear deformation of inhomogeneous viscous fluids. 1. Theory. Tectonophysics, 5(3), 211-234 (doi: 10.1016/0040-1951(68)90065-6)

Goldsby DL and Kohlstedt DL (2001) Superplastic deformation of ice: experimental observations. J. Geophys. Res., Solid Earth, 106(B6), 11017-11030 (doi: 10.1029/2000JB900336)

Gow AJ (1968a) Bubbles and bubble pressures in Antarctic glacier ice. J. Glaciol., 7(50), 167-182 (doi: 10.3189/S0022143000030975)

Gow AJ (1968b) Deep core studies of the accumulation and densification of snow at byrd station and little America V, Antarctica. USACE Cold Regions Research and Engineering Laboratory Res., Rep 197, Hanover, NH

Hansen DP and Wilen LA (2002) Performance and applications of an automated c-axis ice-fabric analyzer. J. Glaciol., 48(160), 159-170 (doi: 10.3189/172756502781831566)

Hirth JP (1972) The influence of grain boundaries on mechanical properties. Metall. Trans., 3(12), 3047-3067 (doi: 10.1007/ BF02661312)

Hudleston PJ (1977) Progressive deformation and development of fabric across zones of shear in glacial ice. In Saxena $S$ and Bhattacharji S eds. Energetics of geological processes. SpringerVerlag, New York, 121-150 (doi: 10.1007/978-3-642-865749_7)
Jacka TH and Maccagnan M (1984) Ice crystallographic and strain rate changes with strain in compression and extension. Cold Reg. Sci. Technol., 8(3), 269-286 (doi: 10.1016/0165-232X(84) 90058-2)

Kipfstuhl S, Pauer F, Kuhs WF and Shoji H (2001) Air bubbles and clathrate hydrates in the transition zone of the NGRIP deep ice core. Geophys. Res. Lett., 28(4), 591-594 (doi: 10.1029/1999GL006094)

Kipfstuhl S and 6 others (2006) Microstructure mapping: a new method for imaging deformation-induced microstructural features of ice on the grain scale. J. Glaciol., 52(178), 398-406 (doi: 10.3189/172756506781828647)

Kipfstuhl S and 8 others (2009) Evidence of dynamic recrystallization in polar firn. J. Geophys. Res., Solid Earth, 114(B05204), 1-10 (doi: 10.1029/2008JB005583)

Llorens M-G and 5 others (2016a) Dynamic recrystallisation of ice aggregates during co-axial viscoplastic deformation: a numerical approach. J. Glaciol., 62(232), 359-377 (doi: 10.1017/jog.2016.28)

Llorens M-G and 6 others (2016b) Full-field predictions of ice dynamic recrystallisation under simple shear conditions. Earth Planet. Sci. Lett., 450, 233-242 (doi: 10.1016/j.epsl.2016.06.045)

Montagnat $M$ and 11 others (2014) Multiscale modeling of ice deformation behavior. J. Struct. Geol., 61, 78-108 (doi: 10.1016/j.jsg.2013.05.002)

Nakawo M and Wakahama G (1981) Preliminary experiments on the formation of elongated air bubbles in glacier ice by stress. J. Glaciol., 27(95), 141-146 (doi: 10.3189/S0022143000011291)

Pauer F, Kipfstuhl S, Kuhs WF and Shoji H (2000) Classification of air clathrates found in polar ice sheets. Polarforschung, 66(3), 31-38

Qi C, Goldsby DL and Prior JP (2017) The down-stress transition from cluster to cone fabrics in experimentally deformed ice. Earth Planet. Sci. Lett., 471, 136-147 (doi: 10.1016/j.epsl.2017.05.008)

Readings CJ and Bartlett JT (1971) Interference phenomena in deformed single crystals of ice. J. Glaciol., 10(59), 269-286 (doi: 10.3189/S002214300001323X)

Reuss A (1929) Berechnung der fliessgrenze von mischkristallen auf grund der plastizitätsbedingung für Einkristalle. Z. Angew. Math Mech., 9, 49-58

Russ JC (2010) The image processing and analysis cookbook, 5th edn., Reindeer Graphics Inc., Asheville, N.C

Russell-Head DS and Budd WF (1979) Ice-sheet flow properties derived from bore-hole shear measurements combined with ice-core studies. J. Glaciol., 24(90), 117-130 (doi: 10.3189/ S0022143000014684)

Sigl M and 26 others (2016) The WAIS Divide deep ice core WD2014 chronology-part 2: annual-layer counting (0-31-kaBP). Clim. Past, 12(3), 769-786 (doi: 10.5194/cp-12-769-2016)

Steinbach F and 6 others (2016) Strain localization and dynamic recrystallization in the ice-air aggregate: a numerical study. Cryosphere, 10, 3071-3089 (doi: 10.5194/tc-10-3071-2016)

Souney JM and 10 others (2014) Core handling and processing for the WAIS divide ice-core project. Ann. Glaciol., 55(68), 15-26 (doi: 10.3189/2014AoG68A008)

Trickett YL, Baker I and Pradhan PMS (2000) The orientation dependence of the strength of ice single crystals. J. Glaciol., 46 (152), 41-44 (doi: 10.3189/172756500781833296)

Van der Veen CJ and Whillans IM (1994) Development of fabric in ice. Cold Reg. Sci. Technol., 22(2), 171-195 (doi: 10.1016/0165232X(94)90027-2)

Voigt W (1928) Lehrbuch der Kristallphysik. Teubner, Leibzig

Voigt DE, Alley RB, Anandakrishnan S and Spencer MK (2003) Icecore insights into the flow and shut-down of Ice Stream C, West Antarctica. Ann. Glaciol., 37, 123-128 (doi: 10.3189/ 172756403781815465)

WAIS Divide Project Members (2013) Onset of deglacial warming in West Antarctica driven by local orbital forcing. Nature, $\mathbf{5 0 0}$ (7463), 440-444 (doi: 10.1038/nature12376)

Weertman J (1983) Creep deformation of ice. Ann. Rev. Earth Planet. Sci., 11(1), 215-240 (doi: 10.1146/annurev.ea.11.050183.001243)

Weikusat I, Kipfstuhl S, Faria SH, Azuma N and Miyamoto A (2009) Subgrain boundaries and related microstructural features in 
EDML (Antarctica) deep ice core. J. Glaciol., 55(191), 461-472 (doi: 10.3189/002214309788816614)

Wilen LA (2000) A new technique for ice-fabric analysis. J. Glaciol., 46(152), 129-139 (doi: 10.3189/172756500781833205)

Wilson CJ, Peternell M, Piazolo S and Luzin V (2014) Microstructure and fabric development in ice: lessons learned from in situ experiments and implications for understanding rock evolution. J. Struct. Geol., 61, 50-77 (doi: 10.1016/j.jsg.2013.05.006)
Zhang Y, Hobbs BE and Jessell MW (1994a) The effect of grain boundary sliding on fabric development in polycrystalline aggregates. J. Struct. Geol., 16, 1315-1325 (doi: 10.1016/ 0191-8141(94)90072-8)

Zhang Y, Hobbs BE and Ord A (1994b) A numerical simulation of fabric development in polycrystalline aggregates with one slip system. J. Struct. Geol., 16, 1297-1313 (doi: 10.1016/01918141(94)90071-X) 